\title{
Correction to: When Women Run, Voters Will Follow (Sometimes): Examining the Mobilizing Effect of Female Candidates in the 2014 and 2018 Midterm Elections
}

\author{
Alauna C. Safarpour ${ }^{1,4}$ - SoRelle Wyckoff Gaynor ${ }^{2}$. Stella M. Rouse $^{2}$ (D) \\ Michele L. Swers ${ }^{3}$ (D)
}

Published online: 20 January 2022

(c) Springer Science+Business Media, LLC, part of Springer Nature 2022

\section{Correction to: Political Behavior \\ https://doi.org/10.1007/s11109-021-09767-x}

In this article the affiliation details of co-author Dr. Alauna Safarpour were incorrectly given as 'Harvard University, Cambridge, MA, USA, and Northwestern University, Evanston, IL, USA' but should have been 'Harvard University, Cambridge, MA, USA, and Northeastern University, Boston, MA, USA.'

Publisher's Note Springer Nature remains neutral with regard to jurisdictional claims in published maps and institutional affiliations.

The original article can be found online at https://doi.org/10.1007/s11109-021-09767-x.

Stella M. Rouse

srouse@umd.edu

Alauna C. Safarpour

alauna_safarpour@hks.harvard.edu

SoRelle Wyckoff Gaynor

sorellew@umd.edu

Michele L. Swers

mls47@georgetown.edu

1 Harvard University, Cambridge, MA, USA

2 University of Maryland, College Park, USA

3 Georgetown University, Washington, USA

4 Northeastern University, Boston, MA, USA 